\title{
The Impact of Water on Particle Emissions from Heated Cooking Oil
}

\author{
Wenhua Chen ${ }^{1,2}$, Pan Wang ${ }^{1}$, Dingchao Zhang ${ }^{1}$, Junjie Liu ${ }^{*}$, Xilei Dai ${ }^{1}$ \\ ${ }^{1}$ Tianjin Key Laboratory of Indoor Air Environmental Quality Control, School of Environmental Science and Engineering, \\ Tianjin University, Tianjin, China \\ ${ }^{2}$ School of Civil Engineering and Architecture, Nanchang University, Nanchang, China
}

\begin{abstract}
Four edible oils, and five mixtures consisting of oil and water in different ratios were heated to investigate the effect of water on the emission characteristics of particles generated by heating cooking oil. The $\mathrm{PM}_{2.5}$ and $0.01-10 \mu \mathrm{m}$ particles emitted during the oil-water heating were monitored with a DustTrak, a condensation particle counter and an Aerodynamic Particle Sizer. The results showed that the $\mathrm{PM}_{2.5}$ mass concentrations and particle number concentrations when heating corn and peanut oil-water emulsions were up to 6 and 50 times higher, respectively, than when heating soybean and canola oilwater emulsions. Emulsions with an oil-water ratio of 6:1 all generated total particle concentrations that exceeded those of mixtures with other ratios. The promoting factors (normalized by the corresponding oil volume to the total volume) for the concentrations of the ultrafine particles, $\mathrm{PM}_{1}$ and $\mathrm{PM}_{2.5}$ ranged from 1.20 to $3.32,1.14$ to 2.50 and 0.71 to 2.14 , respectively. In addition, the ratio between the ultrafine particles $(10-100 \mathrm{~nm})$ and the total particles, and the particle number mode and median diameters changed with the oil-water ratio, but no clear trend was observed. Regression analysis revealed that the effect of water on particle emissions is not statistically significant.
\end{abstract}

Keywords: Oil-water ratio; Cooking; Emission characteristics; $\mathrm{PM}_{2.5}$; Ultrafine particles; Supermicron particles.

\section{INTRODUCTION}

People are indoors approximately $90 \%$ of the time (Nazaroff and Goldstein, 2015), especially in their dwelling. Hence, it is important to maintain good indoor air quality. However, indoor air quality in some areas is poor, caused by both outdoor and indoor sources. The World Health Organization (WHO) (2015) reported that indoor air pollution is 5-10 times higher than outdoor air pollution. Indoor sources are more dominant (Bekö et al., 2015; Acciai et al., 2017; Xu et al., 2018), and several indoor activities that contribute to indoor pollution have been studied, including cooking, smoking, candle burning, etc. (Bekö et al., 2013; Tan et al., 2013; Yu et al., 2015). Among these activities, cooking is one of the most important sources of indoor particulate matter (Amouei Torkmahalleh et al., 2017; Jodeh et al., 2017; Tong et al., 2018), including coarse ( $\mathrm{PM}_{10}$; aerodynamic diameter $<10 \mu \mathrm{m})$, fine $\left(\mathrm{PM}_{2.5}\right.$; aerodynamic diameter $<2.5 \mu \mathrm{m})$ (Gao et al., 2013a; Amouei Torkmahalleh et al., 2017b; Admasie et al., 2019) and ultrafine particles (UFP; aerodynamic diameter $<0.1 \mu \mathrm{m}$ ) (Wang et al., 2015; Amouei Torkmahalleh et al., 2017). Zhao et al. (2019) and

\footnotetext{
${ }^{*}$ Corresponding author.

E-mail address: jjliu@tju.edu.cn
}

Wang et al. (2018) reviewed some severe health problems that could be due to cooking-related emissions, such as respiratory symptoms (Huboyo et al., 2011; Chang et al., 2019), lung cancer (Buonanno et al., 2015; Vu et al., 2017), brain response (Naseri et al., 2019), etc. Therefore, it is essential to take certain measures to remove such cooking pollutants. Domestic kitchen range hoods or canopy hoods are the most common household appliances implemented to reduce exposure in residential kitchens. The BS-EN-61591 standard (IEC, 2011) gave an odor reduction factor to test the ability to extract odors for kitchen range hoods. However, the capture efficiency for particles cannot be represented by the results from the tracer gas test since particles are more difficult to sequester (Lunden et al., 2015). Therefore, to evaluate/improve the particle capture efficiency of domestic kitchens or canopy hoods and reduce the indoor exposure of individuals to cooking pollution, determining the particle emission characteristics from cooking activities is an essential prerequisite.

Table 1 summarizes previous studies of the past two decades regarding the generation of cooking particles from different methods. These studies show that cooking particle generation methods can be divided into four types: water boiling (Yik and Au, 2002; Rim et al., 2012; Lai and Chen, 2015), oil heating (Welch and Kuehn, 2003; Amouei Torkmahalleh et al., 2012; Gao et al., 2013; Tseng and Chen, 2013; Amouei Torkmahalleh et al., 2017a; Zhao et al., 2019), 
Table 1. Summary of previous work regarding the generation of cooking particles.

\begin{tabular}{|c|c|c|c|c|}
\hline References & Method & Pan (mm) & $\mathrm{T}\left({ }^{\circ} \mathrm{C}\right)$ & Comment \\
\hline Yik and $\mathrm{Au}(2002)$ & Water boiling & 380 & 100 & 2 L water \\
\hline Phase et al. (2003) & Oil heating & None & $246-260$ & $0.5-3 \mathrm{~mL} \mathrm{~min} \mathrm{~m}^{-1}$ oleic acid \\
\hline Sjaastad et al. (2010) & Dish cooking & None & $>230$ & Frying beefsteak \\
\hline IEC (2011) & Oil-water heating & 200 & 250 & $48 \mathrm{~mL}$ corn oil $+69 \mathrm{~mL}$ water \\
\hline GB/T 17713-2011 (2011) & Oil-water heating & 200 & 290 & $400 \mathrm{~mL}$ corn oil $+69 \mathrm{~mL}$ water \\
\hline $\begin{array}{l}\text { Amouei Torkmahalleh et } \\
\text { al. (2012) }\end{array}$ & Oil heating & 100 & $205-131$ & $\begin{array}{l}0.2 \text { L oil (olive, peanut, safflower, } \\
\text { soybean, canola, corn, coconut) }\end{array}$ \\
\hline Rim et al. (2012) & Water boiling & None & 100 & $0.75 \mathrm{~L}$ water \\
\hline Tseng et al. (2013) & Oil heating & 185 & $180-210$ & $\begin{array}{l}300 \mathrm{~mL} \text { oil (soybean, olive, } \\
\text { sunflower) }\end{array}$ \\
\hline Gao et al. (2013) & Oil heating & 200 & $113.7-212.3$ & $\begin{array}{l}100 \mathrm{~g} \text { oil (rapeseed, soybean, peanut, } \\
\text { sunflower, olive, blend) }\end{array}$ \\
\hline Lai et al. (2015) & $\begin{array}{l}\text { Water boiling } \\
\text { Oil heating }\end{array}$ & 275 & 100, None & $1 \mathrm{~L}$ water, $60 \mathrm{~mL}$ of oil \\
\hline Li et al. (2017) & Oil-water Heating & None & 265 & $\begin{array}{l}5 \mathrm{~mL} \text { water }+300 \mathrm{~mL} \text { oil (rapeseed, } \\
\text { sunflower, soybean and corn) }\end{array}$ \\
\hline $\begin{array}{l}\text { Amouei Torkmahalleh et } \\
\text { al. (2017) }\end{array}$ & Oil heating & 200 & 250 & $150 \mathrm{~mL}$ corn oil \\
\hline Zhao et al. (2018) & Dish cooking & None & $50-215$ & 15 typical Chinese dishes \\
\hline Zhao et al. (2019) & Oil heating & None & 240 & $\begin{array}{l}50 \mathrm{~mL} \text { oil (olive, soybean, rapeseed, } \\
\text { peanut, corn and sunflower) }\end{array}$ \\
\hline Zhai and Albritton (2020) & Oil heating & 250 & $30-270$ & $\begin{array}{l}120 \mathrm{~mL} \text { oil (olive, canola, vegetable, } \\
\text { corn, peanut, coconut) }\end{array}$ \\
\hline
\end{tabular}

dish cooking (2010; Zhao et al., 2018) and oil-water heating (See and Balasubramanian, 2006; GB/T 17713-2011, 2011; IEC, 2011; Li et al., 2017). Water boiling can stably generate vapor (Yik and $\mathrm{Au}, 2002$ ), but the physical characteristics of vapor are different when they contain grease particles (Lai and Chen, 2015), especially in Chinese cooking (See and Balasubramanian, 2006). Therefore, it is still controversial to use vapor to evaluate cooking emissions instead of airborne fine particles. Dish cooking methods can simulate the particles emitted in practical cooking processes. However, the emission processes are unstable and uncontrollable. For example, Wan et al. (2011) found that the $\mathrm{PM}_{1}$ concentrations from cooking for $40 \mathrm{~min}$ can be up to 8 times higher than that for a cooking time of $10 \mathrm{~min}$. In addition, the particle emission characteristics from dish cooking change with many factors (Amouei Torkmahalleh et al., 2017c; Zhao et al., 2019), including oil type, ingredients, heating temperature, cooking style, indoor air temperature/humidity (Amouei Torkmahalleh et al., 2016), cooking pan (Wallace et al., 2015; Amouei Torkmahalleh et al., 2018; Broomandi et al., 2019) etc.

It was found that oil-based cooking produces more particles than water-based cooking (See and Balasubramanian, 2006; Zhao et al., 2018), and the composition and strengths of cooking fumes generated by dish cooking are highly related to oil type, but temperature has no effect (Zhao et al., 2018). Previous studies (Welch and Kuehn, 2003; Amouei Torkmahalleh et al., 2012; Gao et al., 2013; Tseng and Chen, 2013; Amouei Torkmahalleh et al., 2017a; Zhao et $a l ., 2019)$ have conducted additional research on oil heating activities. The results in these studies (Amouei Torkmahalleh et al., 2012; Gao et al., 2013a, b) indicated that the particle emission strengths of pure heated oil depended on both oil type and heating temperature. Moreover, a few studies (Welch and Kuehn, 2003; Amouei Torkmahalleh et al., 2013) investigate the influence of additives on particle emission from heated oil. Amouei Torkmahalleh et al. $(2013,2016)$ found that sea salt, table salt and black pepper reduced the particle number emission rates, but the effect of turmeric and garlic powder was not significant. ASHRAE 1151 (Welch and Kuehn, 2003) provided a cooking simulator that sprayed a mixture of oleic acid and isopropyl alcohol (in a 2:1 ratio) into a hot plate to generate particles. The particle size distribution was similar to that of cooking hamburger (Schrock et al., 2006) but was different from that of general cooking (See and Balasubramanian, 2006; Lunden et al., 2015). Unlike ASHRAE 1151, the approach to a cooking simulator in mainstream standards (GB/T 17713-2011, 2011; IEC, 2011) is oil-water heating, but this method does not provide information about the particle distribution. Li et al. (2015) measured the particle emission from four heated edible oils (rapeseed, sunflower, soybean and corn oils) with autodripping water and found that the thermal cracking products and the cooking fumes were related to both oil type and the presence of water. However, these mainstream standards (GB/T 17713-2011, 2011; IEC, 2011) and study (Li et al., 2017) only considered one oil-water ratio. Our previous study (Zhang et al., 2019) found that the total concentrations of VOCs emitted from vegetable oils significantly increased with an increasing oil-water ratio, but the effect of the amount of water on particle emissions from heated oil has not yet been determined.

Therefore, the present research aimed to identify the impact of water on the particle emission characteristics from oil-water heating. To systematically study particles ranging 
from $0.01-10 \mu \mathrm{m}$ emitted during oil-water heating, four edible oils (corn, canola, peanut and soybean) with five oilwater ratios were measured by a condensation particle counter (CPC) and an Aerodynamic Particle Sizer (APS). The $\mathrm{PM}_{2.5}$ concentration levels were also acquired by using the DustTrak aerosol monitor. The results of the present study are expected to provide full-size $(0.01-10 \mu \mathrm{m})$ characteristics.

\section{METHODOLOGY}

\section{Experimental Apparatus}

The experiment was carried out in a fume hood with a constant flow rate of $360 \mathrm{~m}^{3} \mathrm{~h}^{-1}$. The fume hood was composed of a canopy hood and a cuboid enclosure, as shown in Fig. 1. The size of the cuboid enclosure was $600 \mathrm{~mm} \times 600 \mathrm{~mm} \times$ $1000 \mathrm{~mm}$. A HEPA filter was installed under the fume hood to minimize the background particle concentrations and the turbulent fluctuations induced from the makeup air. The experimental apparatus was placed in an air-conditioned room with an air temperature of $24 \pm 1{ }^{\circ} \mathrm{C}$.

As shown in Fig. 1, this cooking simulator consisted of an electric stove, a nonstick pot, a thermostat, a liquid feed system, etc. The electric stove with the nonstick pot was placed on the center of the HEPA filter. The diameter of the nonstick pot and the effective heating area of the electric stove were both $240 \mathrm{~mm}$. The thickness of the nonstick pot was $5 \mathrm{~mm}$, and a thermocouple was mounted in the pot to measure the heating temperature. The heating temperature of the pan was maintained at $260 \pm 1{ }^{\circ} \mathrm{C}$ by the thermostat. In addition to ASHRAE 1151, the liquid feed system consisted of an air compressor, a conical-tip ejector nozzle, an agitator, a liquid peristaltic pump, etc., and an agitator emulsified the water and oil in a container.

Four edible oils (corn, canola, peanut and soybean) and five oil-water ratios $\left(\mathrm{V}_{\text {oil }}: \mathrm{V}_{\text {water }}=1: 0\right.$ [pure oil], 6:1, 2:1, 1:1 and 1:2) were chosen for measurements; the fatty acid content of these oils is provided in our previous work (Zhang et al., 2019). The oil-water ratio $1: 1$ and $6: 1$ was referred to the standard IEC (2011) and GB/T 17713-2011 (2011), respectively. The oil-water mixture was made by an agitator; the stability and repeatability of the oil-water mixture is ensured by using a viscosimeter to monitor the viscosity. The oil-water mixture was fed to the ejector nozzle via the liquid peristaltic pump, and the liquid feed rate was $1.5 \mathrm{~mL} \mathrm{~min}^{-1}$. The air compressor was used to atomize the spray from the nozzle, and the flow rate was $3 \mathrm{~L} \mathrm{~min}^{-1}$. The ejector nozzle was fixed at $130 \mathrm{~mm}$ above the pan, so the droplets could uniformly cover the heating surface. Each case repeated 5 times.

\section{Instrumentation}

In this study, particle mass and number concentration measurements were collected by implementation of three instruments in real time. A condensation particle counter (AMG1500) was applied to obtain the number concentration and particle size distribution in a nanometer size range from 13 to $550 \mathrm{~nm}$ over 96 channels. The sampling flow rate was

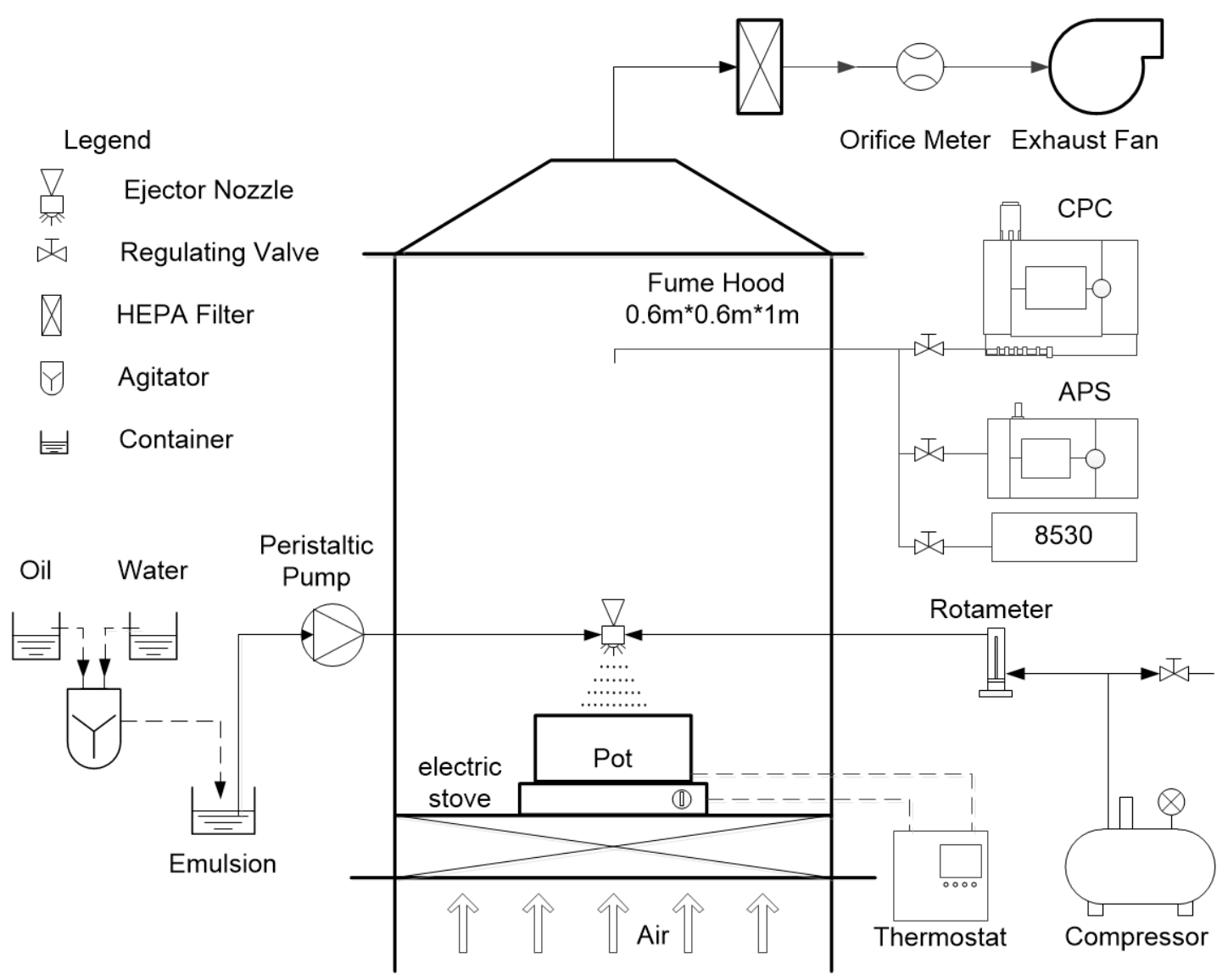

Fig. 1. Schematic of experimental apparatus in fume hood. 
set to $6.0 \mathrm{~L} \mathrm{~min}^{-1}$. The sample scan time was $5 \mathrm{~min}$ (Wallace et al., 2004). A better understanding of the different particle emission characteristics between oil types or oil-water ratios is still needed; since CPC only monitored the particles with diameters between 0.013 and $0.550 \mu \mathrm{m}$, the TSI Model 3321 Aerodynamic Particle Sizer (APS; St. Paul, MN, USA), which measures particle size distribution and number concentration in the range from 0.542 to $20 \mu \mathrm{m}$ over 50 channels, was utilized. Approximation of fine particle $\left(\mathrm{PM}_{2.5}\right)$ mass concentration was measured at 1-min intervals via the TSI Model 8530 DustTrak aerosol monitor fitted with $2.5 \mu \mathrm{m}$ size-selective inlets. The sampling flow rate and time were set as $3.0 \mathrm{~L} \mathrm{~min}^{-1}$ and $1 \mathrm{~min}$, respectively. DustTrak measuring techniques are based on light scattering. The three instruments were connected through a sample diluter with a dilution ratio of 1:50. The sampling probe was placed at a height of $70 \mathrm{~cm}$ above the pan. The emission and sampling period were $30 \mathrm{~min}$.

\section{RESULTS AND DISCUSSION}

\section{PM2.5 Concentrations and Emission Rates}

Fig. 2 shows the $\mathrm{PM}_{2.5}$ mass concentrations and standard deviation (SD) during oil-water heating at $260^{\circ} \mathrm{C}$ for four edible oils and five oil-water ratios. The corresponding background concentration of $\mathrm{PM}_{2.5}$ for each case has been subtracted from the result in Fig. 2. The averaged background $\mathrm{PM}_{2.5}$ concentration for all cases is $0.076 \pm 0.033 \mathrm{mg} \mathrm{m}^{-3}$; the background $\mathrm{PM}_{2.5}$ is generated by heating the empty pan since the particles in the outdoor air are trapped by the HEPA filter. It can be seen that similar levels and change characteristics of $\mathrm{PM}_{2.5}$ concentrations have been exhibited between corn oil and peanut oil. In addition, canola oil and soybean oil also share similar levels and change characteristics with each other. However, corn oil and peanut oil generated higher $\mathrm{PM}_{2.5}$ concentrations compared to that of canola oil and soybean oil, exhibiting concentrations up to 6 times higher. This might be due to canola oil and soybean oil having higher smoke point temperatures than corn oil and peanut oil (Zhang et al., 2019). This phenomenon was in agreement with a previously published oil cooling experiment (Amouei Torkmahalleh et al., 2012). Fig. 2 also shows that the $\mathrm{PM}_{2.5}$ concentration decreases with a reducing oil-water ratio for corn oil and peanut oil. However, there is a marked increase in $\mathrm{PM}_{2.5}$ concentration when the oil-water ratio is $1: 1$, especially for corn oil and peanut oil. The reason might be that the strong thermal cracking products were larger

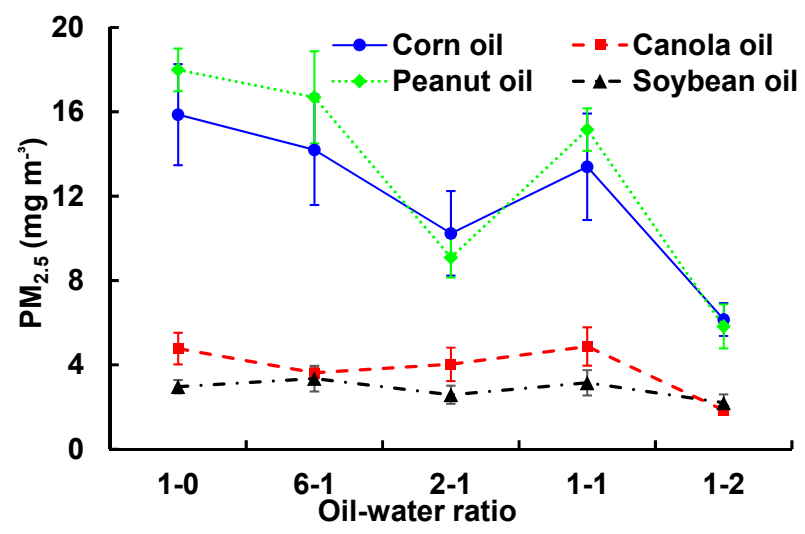

Fig. 2. Mean and standard deviation of $\mathrm{PM}_{2.5}$ concentrations during oil-water heating at $260^{\circ} \mathrm{C}(\mathrm{N}=5)$.

particles when the oil-water ratio was $1: 1$. The $\mathrm{PM}_{2.5}$ concentrations of the four types of oils were the smallest when the oil-water ratio was 1:2.

A regression (Wallace et al., 2015) was performed on the oil-water ratio (Table 2) for four oils; the results demonstrate that the effect of the oil-water ratio on the change of $\mathrm{PM}_{2.5}$ concentrations is not statistically significant $(\mathrm{P}>0.05)$.

\section{Particle Concentration and Size Distribution}

Fig. 3 shows the number distribution frequency of particles $(0.01-10 \mu \mathrm{m})$ from heating different oil-water ratios at $260^{\circ} \mathrm{C}$, with particle sizes almost below $1 \mu \mathrm{m}$ based on the number distribution. The measurement data were averaged from the 30-min heating episodes, with the background concentration subtracted. Background measurements were also conducted in the sampling location, showing that all background concentrations were below $2 \times 10^{2} \mathrm{~cm}^{-3}$. In Fig. 3, averaged number distribution frequency of particles emitted from the heating of different oils are quite different, the similar result was found in the previous study (Amouei Torkmahalleh et al., 2012). It might due to different smoke temperature and chemical compositions of five types of oils, detailed information listed in our previous study (Zhang et al., 2019). As depicted in Fig. 3, the oil-water ratio had a significant effect on the particle size distributions, especially for that of ultrafine particles $(10-100 \mathrm{~nm})$. The particle number mode diameter was changed with different oil-water ratios for the four edible oils, but the frequency did not change significantly with the oil-water ratios. Single-modal distributions are observed in Fig. 3 for the corn, peanut and

Table 2. Regression of $\mathrm{PM}_{2.5}$ concentrations on oil-water ratio.

\begin{tabular}{|c|c|c|c|c|c|}
\hline & & B (slope) & Standard error & t-Stat & P-value \\
\hline \multirow[t]{2}{*}{ Corn oil } & Intercept & 3.94 & 3.26 & 1.20 & 0.31 \\
\hline & Oil-water ratio & 11.97 & 4.58 & 2.61 & 0.07 \\
\hline \multirow[t]{2}{*}{ Canola oil } & Intercept & 2.04 & 1.53 & 1.33 & 0.27 \\
\hline & Oil-water ratio & 2.66 & 2.15 & 1.23 & 0.30 \\
\hline \multirow[t]{2}{*}{ Peanut oil } & Intercept & 2.64 & 5.00 & 0.52 & 0.63 \\
\hline & Oil-water ratio & 15.37 & 7.01 & 2.19 & 0.11 \\
\hline \multirow[t]{2}{*}{ Soybean oil } & Intercept & 2.15 & 0.56 & 3.83 & 0.03 \\
\hline & Oil-water ratio & 1.05 & 0.79 & 1.33 & 0.27 \\
\hline
\end{tabular}



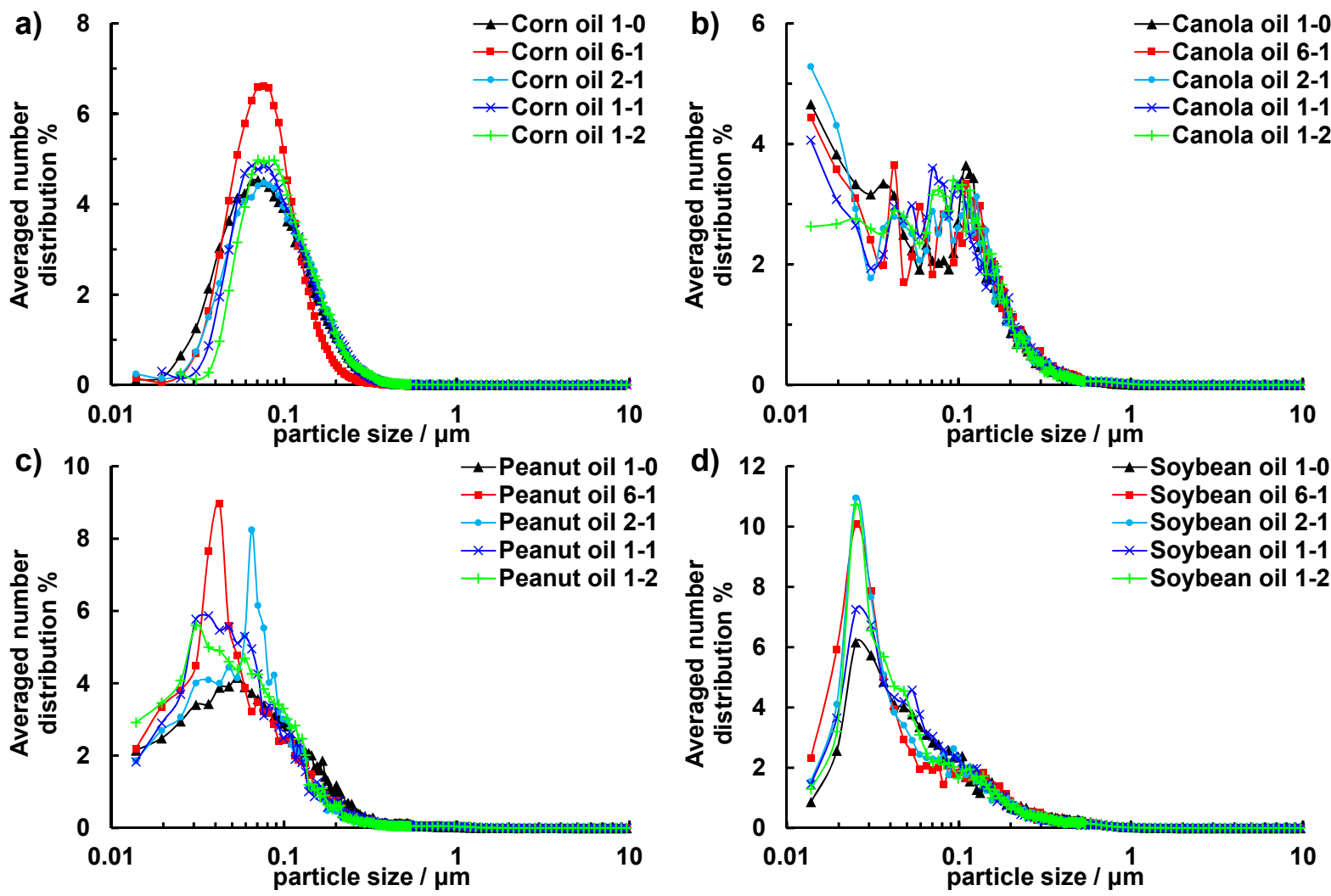

Fig. 3. Averaged number distribution frequency of particles $(0.01-10 \mu \mathrm{m})$ emitted from the heating of different oil-water ratios at $260^{\circ} \mathrm{C}$.

soybean oils at different oil-water ratios. The particle number distribution frequency for canola oil showed a peak location at particles $<0.013 \mathrm{~nm}$. We also compared the particle size distributions determined in this study with those of previous studies (Wallace et al., 2004; Amouei Torkmahalleh et al., 2012; Jorgensen et al., 2013). The number distribution frequency of the four pure oils presented in Fig. 3 agreed well with the shapes of particle size distributions measured by Amouei Torkmahalleh et al. (2012). As shown in Fig. 3(a), the series of heated corn oil-water mixtures generated similar particle size distributions as those generated by frying flour tortillas (Wallace et al., 2004) (see Fig. S1(a)) and frying bacon (Jorgensen et al., 2013) (see Fig. S1(b)), which were also monitored by a CPC. Fig. 3(b) shows that the series of heated canola oil-water mixtures generated a particle size distribution close to those of the steaming and boiling methods (See and Balasubramanian, 2006).

A regression (Wallace et al., 2015) was also performed on the oil-water ratio (Table 3) for four oils; the results demonstrate that the effect of the oil-water ratio on the change of particle $(0.01-10 \mu \mathrm{m})$ concentrations is not statistically significant $(\mathrm{P}>0.05)$.

Fig. 4 depicts the ratio of ultrafine particles $(10-100 \mathrm{~nm})$ to total particles from the heating of different oil-water ratios at $260^{\circ} \mathrm{C}$. The averaged ratios for each case range from 55$-75 \%$. The oil-water ratio has an obvious effect on the particle ratio regardless of oil type and oil-water ratio. However, there are no similar trends between the different oils with the change in the oil-water ratio. The highest ratio of ultrafine particles -to total particles existed at an oil-water ratio of $6: 1$, except for soybean oil. The reason might be that the small amount of liquid water may vaporize so rapidly that an explosion may occur. These explosions have been termed "vapor explosions," "explosive boiling," or "rapid vapor explosions" (McIntyre, 1978; Manzello et al., 2003), then promotes the production of more ultrafine particles (Fig. 3). The similar result was found in the previous study (Li et al., 2017): Sprayed water into the heated oil promotes the production of ultrafine particles $(0.030-0.109 \mu \mathrm{m})$. The data depicted in Fig. 4 are also consistent with previous research (See and Balasubramanian, 2006; Jorgensen et al., 2013). The results agree with reported Chinese cooking activities (See and Balasubramanian, 2006), and the ratios of ultrafine particles (10-100 nm) to total particles for stir-frying, steaming and boiling are $69 \%, 90 \%, 55 \%$ and $62 \%$, respectively. As reported for the frying of bacon (Jorgensen et al., 2013), the ratio of ultrafine particles $(10-100 \mathrm{~nm})$ to total particles from three types of bacon ranged from $35-70 \%$. However, the particle ratio for heated oil-water mixtures is smaller than in oil cooling, and the particle ratios for heated corn, peanut, canola and soybean oils ranged from 0.76 to 0.99 with temperature cooling $\left(190-130^{\circ} \mathrm{C}\right)$ (Amouei Torkmahalleh et al., 2012).

A regression (Wallace et al., 2015) was also performed on the oil-water ratio (Table 4) for four oils; the results demonstrate that the effect of the oil-water ratio on the ratios of ultrafine particles $(10-100 \mathrm{~nm})$ to total particles is not statistically significant $(\mathrm{P}>0.05)$. 
Table 3. Regression of particle $(0.01-10 \mu \mathrm{m})$ concentrations on oil-water ratio.

\begin{tabular}{llllll}
\hline & & B (slope) & Standard error & t-Stat & P-value \\
\hline Corn oil & Intercept & $1.57 \times 10^{6}$ & $3.15 \times 10^{6}$ & 0.49 & 0.65 \\
Canola oil & Oil-water ratio & $5.05 \times 10^{6}$ & $4.42 \times 10^{6}$ & 1.14 & 0.33 \\
& Intercept & $8.85 \times 10^{5}$ & $9.37 \times 10^{5}$ & 0.94 & 0.41 \\
Peanut oil & Oil-water ratio & $1.23 \times 10^{5}$ & $1.31 \times 10^{5}$ & 0.93 & 0.41 \\
& Intercept & $2.64 \times 10^{5}$ & $7.04 \times 10^{5}$ & 0.37 & 0.73 \\
Soybean oil & Oil-water ratio & $1.11 \times 10^{6}$ & $9.87 \times 10^{5}$ & 1.12 & 0.34 \\
& Intercept & $3.42 \times 10^{5}$ & $3.84 \times 10^{5}$ & 0.09 & 0.93 \\
\hline
\end{tabular}

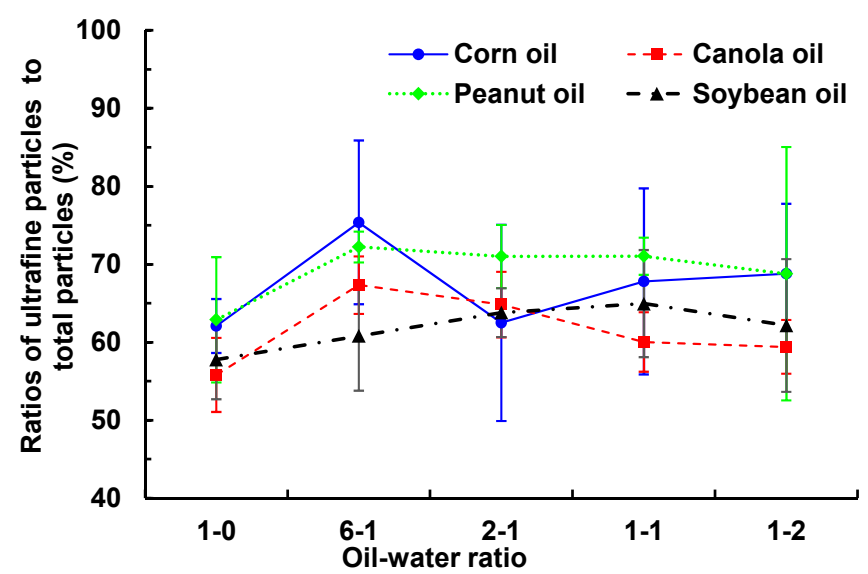

Fig. 4. Ratios of ultrafine particles $(10-100 \mathrm{~nm})$ to total particles emitted from the heating of different oil-water ratios at $260^{\circ} \mathrm{C}$.

Table 4. Regression of ratios of ultrafine particles $(10-100 \mathrm{~nm})$ to total particles on oil-water ratio.

\begin{tabular}{llllll}
\hline & & B (slope) & Standard error & t-Stat & P-value \\
\hline Corn oil & Intercept & 74.92 & 9.67 & 7.74 & 0.004 \\
Canola oil & Oil-water ratio & -14.91 & 13.57 & -1.09 & 0.35 \\
& Intercept & 61.11 & 7.05 & 8.67 & 0.003 \\
Peanut oil & Oil-water ratio & 0.53 & 9.88 & 0.05 & 0.96 \\
& Intercept & 73.15 & 5.20 & 14.06 & 0.001 \\
Soybean oil & Oil-water ratio & -5.92 & 7.29 & -0.81 & 0.47 \\
& Intercept & 67.00 & 2.93 & 22.81 & 0.0001 \\
& Oil-water ratio & -7.61 & 4.12 & -1.84 & 0.16 \\
\hline
\end{tabular}

Fig. 5 presents the variations of particle number mode diameter and mean diameter from the heating of different oil-water ratios at $260^{\circ} \mathrm{C}$. As shown in Fig. 5(a), the effect of oil type on the particle number mode diameter is more significant than that of the oil-water ratio. The influence of oil-water ratio on particle number mode diameter is less visible, it might be due to the particle number mode diameter is more dependent on the oil type. The particle number mode diameter for the series of corn oil-water emulsions ranged from $59-87 \mathrm{~nm}$, the particle number mode diameter for the series of peanut oil-water emulsions ranged from 31-54 nm, the particle number mode diameter for the series of canola oil-water emulsions ranged from 93-127 nm, and the particle number mode diameter for the series of soybean oil-water emulsions ranged from $26-32 \mathrm{~nm}$. The results are in agreement with the previous research summarized by Abdullahi et al. (2013), where different cooking activities generated particle number mode diameters ranging from 20 to $150 \mathrm{~nm}$. Besides, it can be found that the particle number mode diameter for the four series of oil-water emulsions almost greater than the test of emitted during heating oil at $197^{\circ} \mathrm{C}$ (Amouei Torkmahalleh et $a l ., 2012)$. The heating oil generated particle number mode diameters ranging from 11 to $50 \mathrm{~nm}$ (Amouei Torkmahalleh et al., 2012). The difference may be attributed to two reasons; one is the heating temperature, two is most of particles emitted during heating oil is produced by the evaporation without the effect of water.

As shown in Fig. 5(b), the highest number median diameter (NMD) existed for pure heated oil because the water was beneficial for producing larger-diameter particles. The particle number median diameter for the series of corn oil-water emulsions ranged from $87-110 \mathrm{~nm}$, the particle number median diameter for the series of peanut oil-water emulsions ranged from $70-81 \mathrm{~nm}$, the particle number 

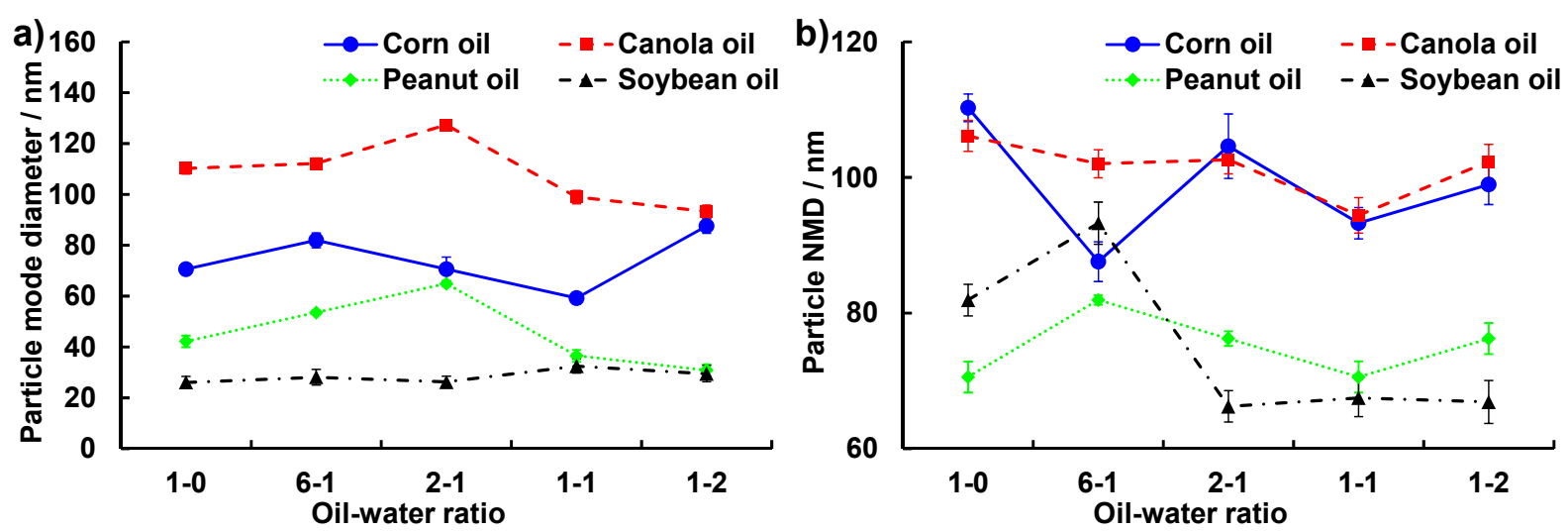

Fig. 5. (a) Particle number mode diameter distribution and (b) particle number median diameter (NMD) distribution of particles emitted from the heating of different oil-water ratios at $260^{\circ} \mathrm{C}$.

median diameter for the series of canola oil-water emulsions ranged from $94-106 \mathrm{~nm}$, and the particle number median diameter for the series of soybean oil-water emulsions ranged from $67-91 \mathrm{~nm}$.

Fig. 6 shows the calculated cumulative volume distribution frequency of particles $(0.01-10 \mu \mathrm{m})$ from the heating of different oil-water ratios at $260^{\circ} \mathrm{C}$. The effects of oil type and oil-water ratio on the cumulative volume distribution frequency were both significant. The thermal cracking products are different between oil types and when the oilwater ratio is modified. The largest volume median diameter (VMD; Dv0.5) in Fig. 6 indicates that the mixture of oil and water produced a larger particle diameter, especially for the oil-water ratio of $6: 1$. Two sharp increases in the cumulative frequency are presented in the ranges of $0.01-1 \mu \mathrm{m}\left(\mathrm{PM}_{1}\right)$ and $5-10 \mu \mathrm{m}$. The volume ratio of $\mathrm{PM}_{1}$ to total particles ranged from $20-60 \%$ for the four oil types. This result is in agreement with the oil heating experiment conducted by Gao et al. (2013b). However, Gao et al. (2013b) did not detect particles $>5 \mu \mathrm{m}$. This discrepancy might be that larger particle sizes cannot be detected at a long distance from the instrument due to gravitational deposition. Another reason might be due to the use of different emission methods.

Fig. 6 also presents the volume median diameter for the different cases; the VMD changed with the changing oilwater ratio. Fig. 7(a) further shows the VMD distribution from the heating of different oil-water ratios. The largest VMDs within all four oil types was at an oil-water ratio of $6: 1$, while the smallest VMDs for the four types of oil all existed in the pure heated oil. To investigate the volume distribution width, a span index is defined as (Dv0.9 Dv0.1)/Dv0.5 (Gao et al., 2013). As shown in Fig. 7(b), the span index ranges from 3-20, which represents a very wide width of size distribution. The smallest space index for all four oil types existed at oil-water ratios of $6: 1$.

\section{Impact of Water on Emission Rate}

To further determine the influence of water on particle emission, the particle number concentrations of UFP, $\mathrm{PM}_{1}$ and $\mathrm{PM}_{10}$ and the mass of $\mathrm{PM}_{2.5}$ in the samples of different oil-water ratios were normalized by the corresponding ratio of oil to total volume. The corresponding pure oils were defined as the reference value (promoting factor $=1$ ):

promoting factor $=\left(C_{i} /\right.$ oil-ratio $\left._{i}\right) / C_{1-0}$

where $i$ is the case of corresponding oil at different oil-water ratios, $C_{i}$ is the concentration of case $i, C_{1-0}$ is the concentration of corresponding pure oil, oil-ratio ${ }_{i}$ is the oil ratio of corresponding oil at different oil-water ratios (range from $0.33-0.86$ ). And the results are presented in Fig. 8. Fig. 8 shows that water increases the particle number or mass concentration, especially for UFP. The promoting factor for UFP ranges from 1.20 (canola oil-water at 1:2) to 3.32 (corn oil-water at 6:1). The promoting factor for $\mathrm{PM}_{1}$ ranges from 1.14 (canola oil-water at 1:2) to 2.50 (corn oil-water at 6:1). The promoting factor of $\mathrm{PM}_{2.5}$ ranges from 0.71 (peanut oilwater at $1: 2$ ) to 2.14 (soybean oil-water at 1:2). The promoting factor for $\mathrm{PM}_{10}$ ranges from 1.13 (canola oilwater at 1:2) to 2.49 (corn oil-water at 6:1). Fig. 8 also shows that water has the highest promoting factor for all oil types with an oil-water ratio of $6: 1$. The reason might be that the small amount of liquid water may vaporize so rapidly that an explosion may occur. These explosions have been termed "vapor explosions," "explosive boiling," or "rapid vapor explosions" (McIntyre, 1978; Manzello et al., 2003), then promotes the production of more ultrafine particles (Li et al., 2017). Besides, it is likely that with the increasing amount of water, the lipid (oil and fat) oxidation rate initially increases and then eventually decreases (Chan, 1987; Binks and Lumsdon, 2000). However, the regression results in Table 2 and Table 3 demonstrate that the effect of the oilwater ratio on the change of $\mathrm{PM}_{2.5}$ and particle number concentrations is not statistically significant $(\mathrm{P}>0.05)$. Correlational analyses were further conducted between different cooking oils at the same oil-water ratio (Table 5). The averaged correlation coefficient of particle emissions between different cooking oils at the same oil-water ratio ranges from $0.89-0.98$, showing a strong correlation.

\section{CONCLUSIONS}

Our results indicate that the mixtures consisting of corn or peanut oil and water produced more particle mass and 

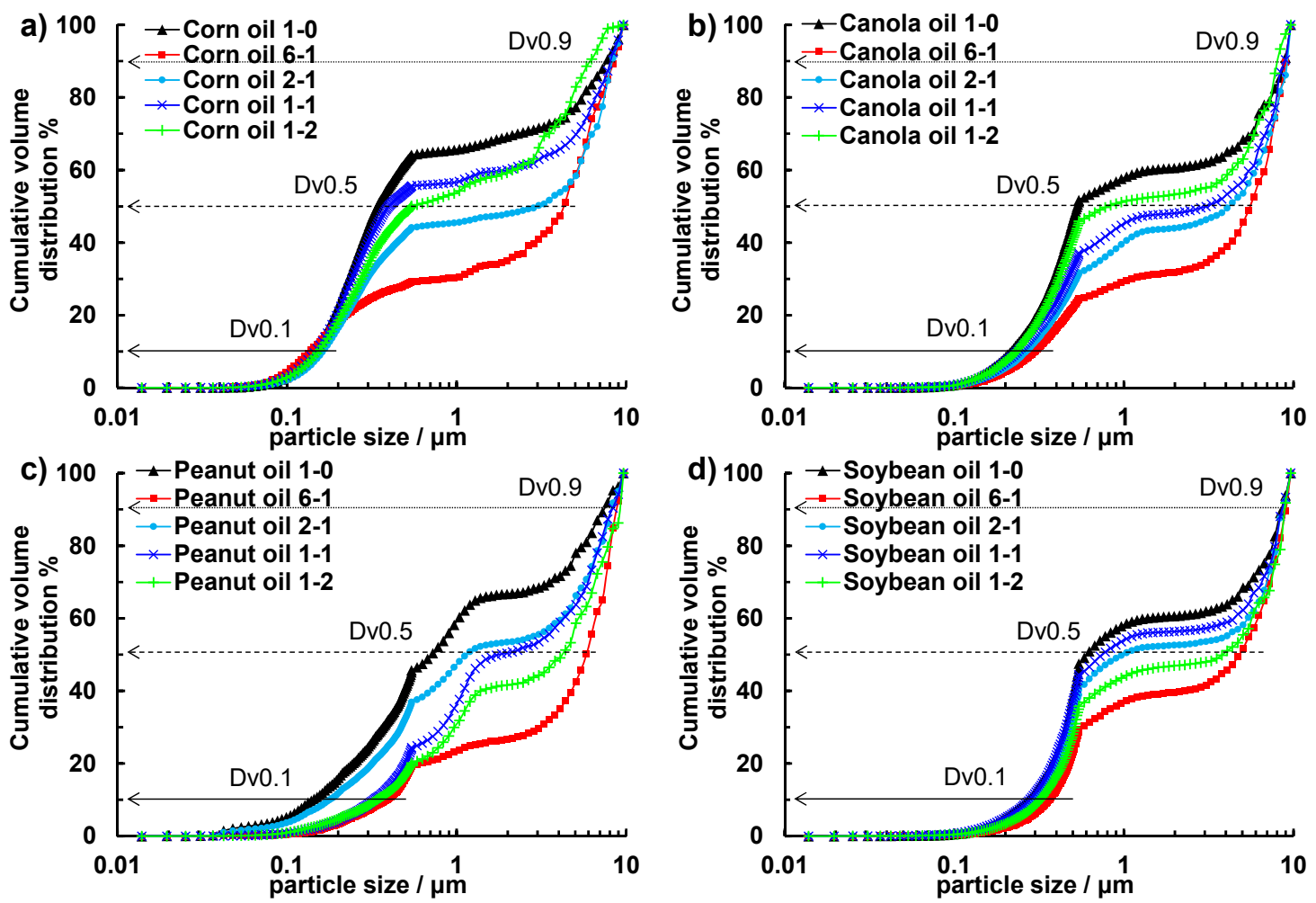

Fig. 6. Cumulative volume distribution frequency of particles $(0.01-10 \mu \mathrm{m})$ emitted from the heating of different oil-water ratios at $260^{\circ} \mathrm{C}$.
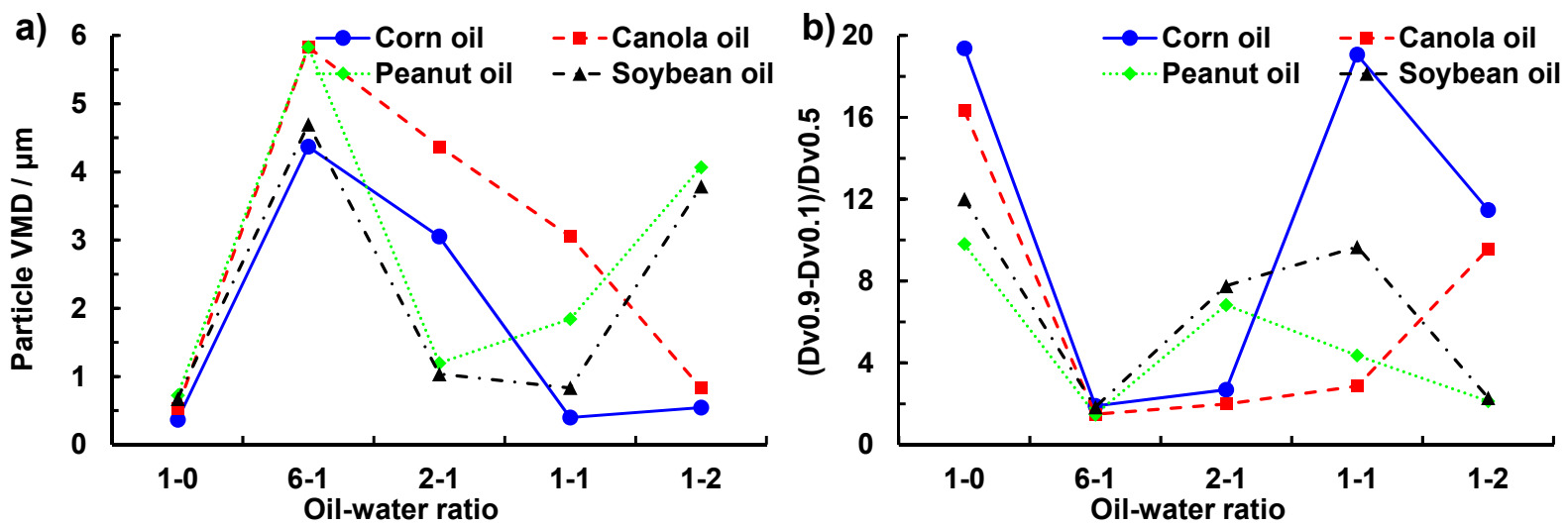

Fig. 7. (a) Particle volume median diameter distribution of particles emitted from the heating of different oil-water ratios at $260^{\circ} \mathrm{C}$ and (b) volume span index of different oil-water ratios at $260^{\circ} \mathrm{C}$.

higher number concentrations than those observed for the other oils, either pure or mixed with water. By contrast, the mixtures consisting of soybean or canola oil and water generated lower particle concentrations than those measured for the other oils, either pure or mixed with water. The $\mathrm{PM}_{2.5}$ mass and particle number concentrations associated with heating the corn and peanut oil-water emulsions exceeded those associated with the soybean and canola oil-water emulsions by up to 6 and 50 times, respectively. Thus, our study provides information on choosing edible oils for real cooking activities that reduce one's exposure to cooking fumes.

Regression analysis revealed that the effect of water on particle emissions is not statistically significant. Heating mixtures with an oil-water ratio of 6:1 generated higher total number concentrations. The shape of the particle number distribution was not obviously affected by the amount of water, but the ratio between the ultrafine particles (10$100 \mathrm{~nm}$ ) and the total particles, and the particle number mode and median diameters changed with the oil-water ratio, although no clear trend was observed. The promoting factors (normalized by the corresponding oil volume to the total volume) for the UFP number concentration, the $\mathrm{PM}_{1}$ number concentration and the $\mathrm{PM}_{2.5}$ mass concentration ranged from 1.20 to $3.32,1.14$ to 2.50 and 0.71 to 2.14 , respectively. 

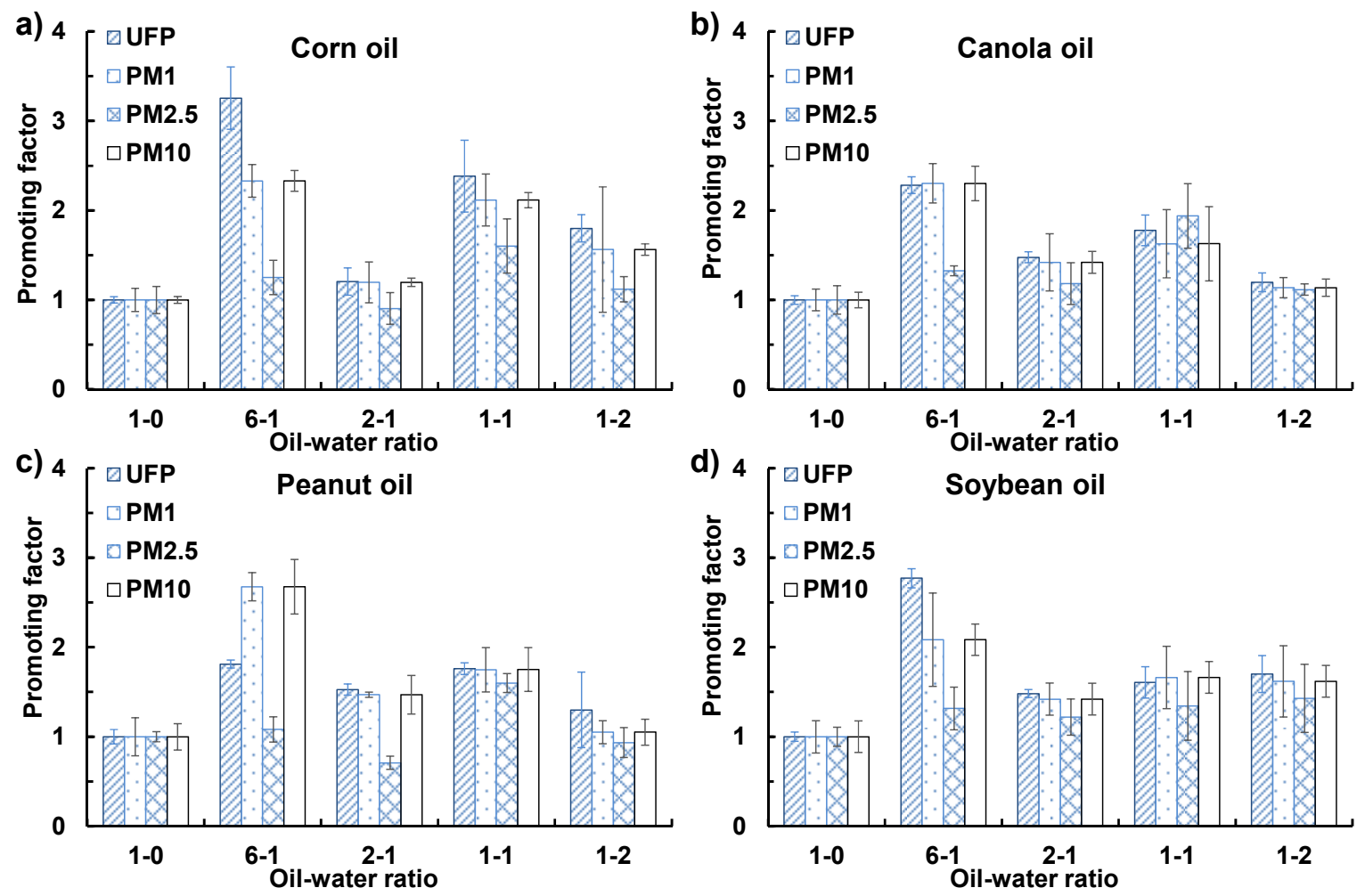

Fig. 8. Influence of water on particle emissions: (a) corn oil, (b) peanut oil, (c) canola oil, (d) soybean oil.

Table 5. Averaged correlation coefficient of particle emissions between different cooking oils at the same oil-water ratio.

\begin{tabular}{lllll}
\hline & Corn oil & Canola oil & Peanut oil & Soybean oil \\
\hline Corn oil & 1 & - & - & - \\
Canola oil & 0.90 & 1 & - & - \\
Peanut oil & 0.95 & 0.89 & 1 & - \\
Soybean oil & 0.94 & 0.98 & 0.91 & 1 \\
\hline
\end{tabular}

\section{SUPPLEMENTARY MATERIAL}

Supplementary data associated with this article can be found in the online version at http://www.aaqr.org.

\section{ACKNOWLEDGMENTS}

This research was supported financially by the National Key Project of the Ministry of Science and Technology, National Key R\&D Program of China (2017YFC0211502). The authors would like to thank the Fotile Company (Ningbo, China) for their technical support during the experiment.

\section{REFERENCES}

Abdullahi, K.L., Delgado-Saborit, J.M. and Harrison, R.M. (2013). Emissions and indoor concentrations of particulate matter and its specific chemical components from cooking: A review. Atmos. Environ. 71: 260-294.

Acciai, C., Zhang, Z., Wang, F., Zhong, Z. and Lonati, G. (2017). Characteristics and source analysis of trace elements in $\mathrm{PM}_{2.5}$ in the urban atmosphere of Wuhan in spring. Aerosol Air Qual. Res. 17: 2224-2234.

Admasie, A., Kumie, A., Worku, A. and Tsehayu, W. (2019). Household fine particulate matter $\left(\mathrm{PM}_{2.5}\right)$ concentrations from cooking fuels: The Case in an urban setting, Wolaita Sodo, Ethiopia. Air Qual. Atmos. Health 12: 755-763.

Amouei Torkmahalleh, M., Goldasteh, I., Zhao, Y., Udochu, N.M., Rossner, A., Hopke, P.K. and Ferro, A.R. (2012). $\mathrm{PM}_{2.5}$ and ultrafine particles emitted during heating of commercial cooking oils. Indoor Air 22: 483-491.

Amouei Torkmahalleh, M., Zhao, Y., Hopke, P.K., Rossner, A. and Ferro, A.R. (2013). Additive impacts on particle emissions from heating low emitting cooking oils. Atmos. Environ. 74: 194-198.

Amouei Torkmahalleh, M., Kaibaldiyeva, U. and Kadyrbayeva, A. (2016). A new computer model for the simulation of particulate matter formation from heated cooking oils using aspen plus. Build. Simul. 10: 535-550.

Amouei Torkmahalleh, M., Gorjinezhad, S., Keles, M., Ozturk, F. and Hopke, P.K. (2017a). Size segregated pm and its chemical composition emitted from heated corn oil. Environ. Res. 154: 101-108.

Amouei Torkmahalleh, M., Gorjinezhad, S., Keles, M., 
Unluevcek, H.S., Azgin, C., Cihan, E., Tanis, B., Soy, N., Ozaslan, N., Ozturk, F. and Hopke, P.K. (2017b). A Controlled study for the characterization of $\mathrm{PM}_{2.5}$ emitted during grilling ground beef meat. J.Aerosol Sci. 103: 132 140.

Amouei Torkmahalleh, M., Gorjinezhad, S., Unluevcek, H.S. and Hopke, P.K. (2017c). Review of factors impacting emission/concentration of cooking generated particulate matter. Sci. Total Environ. 586: 1046-1056.

Amouei Torkmahalleh, M., Ospanova, S., Baibatyrova, A., Nurbay, S., Zhanakhmet, G. and Shah, D. (2018). Contributions of burner, pan, meat and salt to pm emission during grilling. Environ. Res. 164: 11-17.

Bekö, G., Weschler, C.J., Wierzbicka, A., Karottki, D.G., Toftum, J., Loft, S. and Clausen, G. (2013). Ultrafine particles: Exposure and source apportionment in 56 Danish homes. Environ. Sci. Technol. 47: 10240-10248.

Bekö, G., Kjeldsen, B.U., Olsen, Y., Schipperijn, J., Wierzbicka, A., Karottki, D.G., Toftum, J., Loft, S. and Clausen, G. (2015). Contribution of various microenvironments to the daily personal exposure to ultrafine particles: Personal monitoring coupled with GPS tracking. Atmos. Environ. 110: 122-129.

Binks, B. and Lumsdon, S. (2000). Catastrophic phase inversion of water-in-oil emulsions stabilized by hydrophobic silica. Langmuir 16: 2539-2547.

Broomandi, P., Amouei Torkmahalleh, M., Akturk, M., Halif Ngagine, S., Gorjinezhad, S., Ozturk, F., Kocak, M. and Kim, J. (2019). A new exposure route to trace elements in indoor particulate matter. Indoor Air, doi: 10.1111/ina.12641.

Buonanno, G., Giovinco, G., Morawska, L. and Stabile, L. (2015). Lung cancer risk of airborne particles for Italian population. Environ. Res. 142: 443-451.

Chan, H.W.S. (1987). The mechanism of autoxidation. In Autoxidation of unsaturated lipids, Chan, H.W.S. (Ed.), Academic Press, London and Orlando, pp. 1-16.

Chang, T., Wang, J., Lu, J., Shen, Z., Huang, Y., Sun, J., Xu, H., Wang, X., Ren, D. and Cao, J. (2019). Evaluation of indoor air pollution during decorating process and inhalation health risks in Xi'an, China: A case study. Aerosol Air Qual. Res. 19: 854-864.

Evans, G.J., Peers, A. and Sabaliauskas, K. (2008). Particle dose estimation from frying in residential settings. Indoor Air 18: 499-510.

Gao, J., Cao, C., Wang, L., Song, T., Zhou, X., Yang, J. and Zhang, X. (2013a). Determination of size-dependent source emission rate of cooking-generated aerosol particles at the oil-heating stage in an experimental kitchen. Aerosol Air Qual. Res. 13: 488-496.

Gao, J., Cao, C., Zhang, X. and Luo, Z. (2013b). VolumeBased size distribution of accumulation and coarse particles $\left(\mathrm{PM}_{0.1-10}\right)$ from cooking fume during oil heating. Build. Environ. 59: 575-580.

GB/T 17713-2011 (2011) Range hood, Standard GB/T 17713-2011.

Huboyo, H.S., Tohno, S. and Cao, R. (2011). Indoor $\mathrm{PM}_{2.5}$ characteristics and $\mathrm{CO}$ concentration related to waterbased and oil-based cooking emissions using a gas stove.
Aerosol Air Qual. Res. 11: 401-411.

IEC (2011) Household range hoods - Methods for measuring performance. Standard IEC 61591, Ed. 1.1, International Electrotechnical Commission, Geneva, Switzerland.

Jodeh, S., Hasan, A.R., Amarah, J., Judeh, F., Salghi, R., Lgaz, H. and Jodeh, W. (2017). Indoor and Outdoor Air Quality Analysis for the City of Nablus in Palestine: Seasonal Trends of $\mathrm{PM}_{10}, \mathrm{PM}_{5.0}, \mathrm{PM}_{2.5}$, and $\mathrm{PM}_{1.0}$ of Residential Homes. Air Qual. Atmos. Health 11: 229237.

Jorgensen, R.B., Strandberg, B., Sjaastad, A.K., Johansen, A. and Svendsen, K. (2013). Simulated restaurant cook exposure to emissions of PAHs, mutagenic aldehydes, and particles from frying bacon. J. Occup. Environ. Hyg. 10: $122-131$.

Lai, A.C.K. and Chen, J. (2015). Numerical study of cooking particle coagulation by using an eulerian model. Build. Environ. 89: 38-47.

Li, S., Gao, J., He, Y., Cao, L., Li, A., Mo, S., Chen, Y. and Cao, Y. (2017). Determination of time- and size-dependent fine particle emission with varied oil heating in an experimental kitchen. J. Environ. Sci. 51: 157-164.

Lunden, M.M., Delp, W.W. and Singer, B.C. (2015). Capture efficiency of cooking-related fine and ultrafine particles by residential exhaust hoods. Indoor Air 25: 4558.

Manzello, S.L., Yang, J.C. and Cleary, T.G. (2003). On the interaction of a liquid droplet with a pool of hot cooking oil. Fire Safety J. 38: 651-659.

McIntyre, D. (1978). Preferred air speeds for comfort in warm conditions. ASHRAE Trans. 84: 264-277.

Naseri, M., Jouzizadeh, M., Tabesh, M., Malekipirbazari, M., Gabdrashova, R., Nurzhan, S., Farrokhi, H., Khanbabaie, R., Mehri-Dehnavi, H., Bekezhankyzy, Z., Gimnkhan, A., Dareini, M., Kurmangaliyeva, A., Islam, N., Crape, B., Buonanno, G., Cassee, F. and Amouei Torkmahalleh, M. (2019). The impact of frying aerosol on human brain activity. Neurotoxicology 74: 149-161.

Nazaroff, W.W. and Goldstein, A.H. (2015). Indoor chemistry: Research opportunities and challenges. Indoor Air 25: 357-361.

Rim, D., Wallace, L., Nabinger, S. and Persily, A. (2012). Reduction of exposure to ultrafine particles by kitchen exhaust hoods: The effects of exhaust flow rates, particle size, and burner position. Sci. Total Environ. 432: 350356.

Schrock, D.W., Olson, B.A., Urness, R.J., Kuehn, T.H. and Breitenfeldt, A.L. (2006). A new standard method of test for determining the grease particulate removal efficiency of filter systems for kitchen ventilation. ASHRAE Trans. 112: 583-591.

See, S.W. and Balasubramanian, R. (2006). Physical characteristics of ultrafine particles emitted from different gas cooking methods. Aerosol Air Qual. Res. 6: 82-92.

Sjaastad, A.K. and Svendsen, K. (2010). Different types and settings of kitchen canopy hoods and particulate exposure conditions during pan-frying of beefsteak. Indoor Build Environ. 19: 267-274.

Tan, C.C.L., Finney, K.N., Chen, Q., Russell, N.V., Sharifi, 
V.N. and Swithenbank, J. (2013). Experimental investigation of indoor air pollutants in residential buildings. Indoor Build Environ. 22: 471-489.

Tong, X., Wang, B., Dai, W.T., Cao, J.J., Ho, S.S.H., Kwok, T.C.Y., Lui, K.H., Lo, C.M. and Ho, K.F. (2018). Indoor air pollutant exposure and determinant factors controlling household air quality for elderly people in Hong Kong. Air Qual. Atmos. Health 11: 695-704.

Tseng, L.C. and Chen, C.C. (2013). Effect of flow characteristics on ultrafine particle emissions from range hoods. Ann. Occup. Hyg. 57: 920-933.

Vu, T.V., Ondracek, J., Zdimal, V., Schwarz, J., DelgadoSaborit, J.M. and Harrison, R.M. (2017). Physical properties and lung deposition of particles emitted from five major indoor sources. Air Qual. Atmos. Health 10: 114.

Wallace, L.A., Emmerich, S.J. and Howard-Reed, C. (2004). Source strengths of ultrafine and fine particles due to cooking with a gas stove. Environ. Sci. Technol. 38: 2304-2311.

Wallace, L.A., Ott, W.R. and Weschler, C.J. (2015). Ultrafine particles from electric appliances and cooking pans: Experiments suggesting desorption/nucleation of sorbed organics as the primary source. Indoor Air 25: 536-546.

Wan, M.P., Wu, C.L., Sze To, G.N., Chan, T.C. and Chao, C.Y.H. (2011). Ultrafine particles, and $\mathrm{PM}_{2.5}$ generated from cooking in homes. Atmos. Environ. 45: 6141-6148.

Wang, G., Cheng, S., Wei, W., Wen, W., Wang, X. and Yao, S. (2015). Chemical characteristics of fine particles emitted from different chinese cooking styles. Aerosol Air Qual. Res. 15: 2357-2366.

Wang, L., Zheng, X., Stevanovic, S., Wu, X., Xiang, Z., Yu, M. and Liu, J. (2018). Characterization particulate matter from several chinese cooking dishes and implications in health effects. J. Environ. Sci. 72: 98-106.

Welch, W.A. and Kuehn, T.H. (2003). Development of a draft method of test for determining grease removal efficiencies. Final Report ASHRAE 1151-RP, American Society of Heating, Refrigerating and Air-Conditioning Engineers, Inc (ASHRAE), Atlanta.
World Health Organization (WHO) (2015). Who guidelines for indoor air quality: Household fuel combustion. World Health Organization. https://www.who.int/airpollution/gu idelines/household-fuel-combustion/en/.

Xu, P., Zhang, J., Ji, D., Liu, Z., Tang, G., Jiang, C. and Wang, Y. (2018). Characterization of submicron particles during autumn in Beijing, China. J. Environ. Sci. 63: 1627.

Yeung, L.L. and To, W.M. (2008). Size distributions of the aerosols emitted from commercial cooking processes. Indoor Build Environ. 17: 220-229.

Yik, F. and Au, P. (2002). Flow rate and capture efficiency of domestic kitchen exhaust hoods for Chinese households. Int. J. Arch. Sci. 3: 125-134.

Yu, K.P., Yang, K.R., Chen, Y.C., Gong, J.Y., Chen, Y.P., Shih, H.C. and Candice Lung, S.C. (2015). Indoor air pollution from gas cooking in five Taiwanese families. Build. Environ. 93: 258-266.

Zhai, S.R. and Albritton, D. (2020). Airborne particles from cooking oils: Emission test and analysis on chemical and health implications. Sustainable Cities Soc. 52: 101845.

Zhang, D.C., Liu, J.J., Jia, L.Z., Wang, P. and Han, X. (2019). Speciation of VOCs in the cooking fumes from five edible oils and their corresponding health risk assessments. Atmos. Environ. 211: 6-17.

Zhao, Y., Chen, C. and Zhao, B. (2018). Is oil temperature a key factor influencing air pollutant emissions from chinese cooking? Atmos. Environ. 193: 190-197.

Zhao, Y., Liu, L., Tao, P., Zhang, B., Huan, C., Zhang, X. and Wang, M. (2019). Review of effluents and health effects of cooking and the performance of kitchen ventilation. Aerosol Air Qual. Res. 19: 1937-1959.

Zhao, Y., Zhang, Z., Ji, C., Liu, L., Zhang, B. and Huan, C. (2019). Characterization of particulate matter from heating and cooling several edible oils. Build. Environ. 152: 204213. 